\title{
As contribuições da História e Filosofia da Ciência na Formação de Professores: uma análise em periódicos
}

Laura Sued Brandão Santos laurasantos08@gmail.com 0000-0002-3874-4406 Universidade Estadual de Santa Cruz - Brasil

Carine Alves dos Santos Peixoto caripeixoto125@gmail.com 0000-0002-7166-4360 Universidade Estadual de Santa Cruz - Brasil

Maria Elvira do Rego Barros Bello merbbello@uesc.br 0000-0003-1280-1596 Universidade Estadual de Santa Cruz - Brasi

Neurivaldo José de Guzzi Filho

neurivaldo@uesc.br

0000-0001-7366-3858

Universidade Estadual de Santa

Cruz - Brasil

\section{RESUMO}

O presente trabalho traz dados de um estudo exploratório que analisou a produção acadêmica presente em nove periódicos de Ensino de Ciências e Ensino de Física, referente às contribuições da História e Filosofia da Ciência (HFC), nos cursos de formação inicial e continuada de professores de Ciências. O período contemplado por este trabalho compreendeu os anos de 2004 a 2015. O objetivo foi avaliar como estas contribuições têm sido difundidas e abordadas nos cursos de formação de professores nos últimos 11 anos. Observamos que apenas 14 trabalhos foram destinados às contribuições da HFC na Formação de Professores de Ciências e Física, revelando-se uma lacuna expressiva a ser preenchida por pesquisas futuras. Nossos resultados apontam caminhos favoráveis à inserção de temas históricos e filosóficos na formação de professores, mas é preciso que esses resultados tornem-se significativos e instigantes nos espaços formativos, aspectos bastante defendidos em todas as pesquisas.

PALAVRAS-CHAVE: Formação de Professores. História e Filosofia da Ciência Ensino de Ciências. 


\section{INTRODUÇÃO}

É notório que ao se fazer uma análise sobre o ensino de Ciências no Brasil verifica-se uma lacuna entre as propostas de inovação, fruto das pesquisas na área de ensino de Ciências, e as ações desenvolvidas em sala de aula na educação básica (GATTI et al., 2004). A formação de professores de ciências, tanto inicial quanto continuada, é um campo teórico em crescente desenvolvimento, porém, tais cursos não têm conseguido de fato, atingir mudanças efetivas no que diz respeito aos processos de ensino e aprendizagem. Observa-se, pois, que estes não levam em consideração as "crenças e imagens" que estes sujeitos trazem consigo quando iniciam sua formação, sobre o que é importante ensinar, como fazê-lo, entre outros aspectos (CARLOS MARCELO, 1998; GATTI et al., 2004; LEVY; SANMARTí, 2001).

Nesse sentido, alguns estudos (GIL-PEREZ, 1991; CARAVALHO; GIL- PÉREZ, 2006; LEVY; SANMARTÍ, 2001; CARLOS MARCELO, 1998) apontam problemas e dificuldades de caráter formativo nos cursos de formação de professores (inicial e continuada) que precisam ser superados. Tais como a dissociação entre as formações científicas e pedagógicas; a não superação da visão simplista do ensino de Ciências; a insuficiência de trabalhos e de reflexão coletiva; as contradições dos conhecimentos teóricos sobre a aprendizagem das Ciências; as limitações do analisar crítico, referente ao ensino tradicional, e a carência de uma formação necessária capaz de associar o ensino e a pesquisa didática.

Os autores Carvalho e Gil-Perez (2006) indicam as necessidades formativas do professor de ciências, dentre as quais destacamos o conhecimento do conteúdo a ser ensinado. De acordo com os mesmos, o conhecimento específico da disciplina aliado à sua prática docente possibilita ao professor ter a compreensão do quão complexo é o conteúdo que ensina. Para Carvalho e GilPerez (2006), sem esse conhecimento o professor não consegue inovar em suas atividades e passa a ser um transmissor excessivo dos conteúdos. Dessa forma, além de defenderem o saber do conteúdo a ser ensinado, destacam a importância, neste momento, da incorporação da historicidade da ciência, que se torna essencial para o professor poder estruturar e levar para sala de aula discussões acerca do conhecimento científico e da conjuntura de uma época.

A História e Filosofia da Ciência (HFC) se apresenta no Ensino de Ciências na medida em que pode contribuir para: evitar as visões distorcidas sobre o fazer científico, bem como conhecer uma forma de associar os conhecimentos científicos com os problemas que originaram sua construção; proporcionar uma intervenção mais autônoma, reflexiva e qualificada em sala de aula; permitir uma compreensão mais dinâmica, não fechada e refinada dos processos de ensino e aprendizagem e da Ciência (MARTINS, 2007). Nesse sentido, os conteúdos passam a ser contextualizados, podendo oportunizar aos educandos uma visão coerente da Ciência e do fazer científico, longe dos estereótipos e dogmatismos.

É evidente a relevância da dimensão histórica e filosófica na formação de professores de ciências, resultado das implicações teóricas e práticas da HFC (MARANDINO, 2003; DUARTE, 2004). De acordo com Martins (2004), vários cursos de licenciaturas das áreas científicas têm contemplado essa questão, seja por meio de uma disciplina específica, que aborde o conteúdo histórico e filosófico, seja por um intermédio de atividades de disciplinas, em que esses 
elementos se encontram presentes, embora estas ainda necessitem de espaços verdadeiramente mais significativos nos cursos de formação inicial e continuada.

Diante de tais considerações, nosso trabalho teve como objetivo investigar como as pesquisas no Ensino de Ciências, em geral, têm contemplado estudos a respeito das contribuições da HFC nos cursos de formação de professores de Ciências e de Física. Sendo assim, o que tem sido produzido sobre a formação de professores de Ciências em relação ao uso da HFC? Dessa forma, foram selecionados os trabalhos publicados nos principais periódicos de Ensino de Ciências (EC) e de Ensino de Física (EF) no período compreendido entre 2004 a 2015.

\section{2- FUNDAMENTAÇÃO TEÓRICA}

A formação inicial de professores e a formação continuada revela ser uma temática bastante debatida e prioritária nas pesquisas em Ensino de Ciências (BONZANINI; BASTOS, 2013; SOARES et al., 2007). Essas pesquisas são discutidas sob os enfoques do processo de ensino e aprendizagem de conteúdos científicos, das políticas educacionais e de formação de alunos, uma vez que, esses, essencialmente, perpassam pela formação dos profissionais de ensino. O processo formativo ofertado para esses profissionais tem sido alvo de várias críticas, uma delas é a relação entre a má qualidade do ensino de ciências e a deficiente formação do professor, que pode ser vinculada com as questões sociais, culturais e políticas de uma sociedade.

As pesquisas sobre educação mostram que a formação docente no Brasil não foi priorizada, de modo que não houve uma preocupação com as políticas de formação (KRASILCHIK, 1987). Nesse sentido "é preciso pensar a formação docente (inicial e continuada) como momentos de um processo contínuo de construção de uma prática docente qualificada e de afirmação da identidade, da profissionalidade e da profissionalização do professor" (BRASIL, 2009, p.15).

As dificuldades são muitas, por exemplo, a má formação metodológica, a insegurança do estar em sala de aula, a pouca qualidade do planejamento e execução das aulas, a utilização exacerbada dos livros didáticos, a baixa remuneração do docente, as péssimas condições de trabalho, as inadequadas formas de ensino, violência nas escolas, desvalorização do magistério, entre outros fatores (KRASILCHIK, 1987; PONTES et al., 2008). Vale destacar que, apesar das duas décadas que separam os trabalhos desses autores (KRASILCHIK, 1987; PONTES et al., 2008), o discurso permanece o mesmo, as mudanças na valorização profissional foram poucas. E é a partir desse cenário, que os espaços de formação continuada ganham relevância na tentativa de suprir as brechas que a formação inicial deixa. De acordo com Bonzanini e Bastos (2013), tais espaços oportunizam para os educadores a manutenção de atualização, reflexão acerca do papel de professor e a importância dos conteúdos que envolvem a formação cidadão do educando.

Cabe destacar que, tanto os processos de formação inicial quanto continuada precisam contemplar inúmeros aspectos relevantes, que possam subsidiar os desafios propostos diariamente no cotidiano escolar, dos avanços da sociedade contemporânea e consequentemente do notório crescimento dos conhecimentos científico-tecnológicos. A profissão docente requer 
especificidades e necessidades na árdua tarefa de ensinar e de estudar, pois, "transformar essa necessidade em direito é fundamental para o alcance da sua valorização profissional e desempenho em patamares de competência exigidos pela sua própria função social" (BONZANINI; BASTOS, 2013, p.02).

É notório que quando se fala em educação básica de qualidade, temos que refletir principalmente sobre a formação dos professores. É necessário formar professores capacitados para vencer a dicotomia entre a teoria e a prática, ainda presente em muitos cursos de formação, refletindo assim, dificuldades para atuarem no cotidiano da escola, o qual está em constante transformação em virtude dos avanços ocorridos na sociedade. Além disso, pode-se ainda fomentar políticas de investimento e de valorização profissional, implementando programas de formação continuada no intuito de manter os profissionais atualizados em sua prática docente (BRASIL, 2006).

Ultimamente, as políticas educacionais brasileiras têm sido reformuladas e com isso a formação de professores merece atenção especial. Tem-se ampliado a oferta de cursos para formação inicial e continuada do professor, sendo essas mudanças refletidas na diversificação de temas abordados no campo curricular, bem como os enfoques teóricos metodológicos que permeiam a prática dos professores, sobretudo na valorização dos saberes e valores constituídos da profissão (LIMA, 2011).

Ainda nessa perspectiva, as políticas de formação vêm sendo discutidas por meio de princípios gerais e questões particulares concernentes a essa formação. Tais princípios e questões assumem melhorias na qualidade do ensino no âmbito da profissionalização da educação, perpassando por uma articulação entre formação básica, condições de trabalho e formação continuada (BONZANINI; BASTOS, 2013). As discussões que dizem respeito à formação de professores precisam também considerar as transformações econômicas, sócio-políticas e culturais da sociedade com criticidade e reflexividade.

Reportando-nos para a formação dos professores de ciências, geralmente a mesma tem sido pensada como uma tentativa de formar um profissional que incorpore contribuições a partir de uma reflexão teórica sobre o tema. Tem-se como perspectiva a construção de novas estratégias para a formação de recursos humanos para a educação, de forma a incorporar as mudanças dos sistemas produtivos que exigem um novo perfil profissional. Este precisa ser capaz de localizar os desafios mais urgentes de uma sociedade "multimídia e globalizada", em que o rápido desenvolvimento, científico e tecnológico, impõe uma dinâmica de permanente reconstrução de conhecimento, saberes, valores e atitudes.

Surge através de pesquisas, das literaturas e experiências de atividades advindas dos cursos de formação de Ciências, a necessidade de conceber a formação de professores como um processo contínuo de constante movimento de ação-reflexão-ação, pois é dessa forma que "o professor poderá rever seus próprios conhecimentos, sua formação e seu aperfeiçoamento profissional, na busca de novas práticas e metodologias a fim de ministrar um ensino de qualidade e em consonância com o mundo atual" (BONZANINI; BASTOS, 2013).

Diante dos avanços dos conhecimentos e das novas exigências oriundas das Políticas Educacionais que permeiam a profissão docente, a inserção da HFC possibilita ao futuro professor e ao professor em exercício a atualização e aperfeiçoamento constante. Seguindo essa linha de raciocínio, a HFC permite aos 
sujeitos o acesso da análise dos momentos de transformação da ciência e de suas teorias. Para Gagliardi (1988), Giordan e De Vecchi (1996) a utilização da HFC pode contribuir para uma formação pautada na construção de conhecimentos, favorecendo a superação do ensino dogmático e fechado e, consequentemente, levando a compreensão de inciativas científicas como uma conquista obtida através de aproximações, retificações e múltiplas rupturas.

Nesse sentido, entendemos que a inclusão da HFC na formação inicial e continuada do professor pode contribuir de maneira positiva com a construção da identidade docente, uma vez que, o mesmo se torna parte essencial dos processos de renovação educativa, sendo o produtor de saberes da sua própria atividade profissional (PEREIRA; NUÑES, 2007). Desse modo, a formação docente constitui-se de um campo de muitos desafios e peculiaridades, em que se torna necessário pensar e repensar sobre como formarmos nossos professores para as novas tarefas e problemas característicos do fazer escolar.

Portanto, dentre as contribuições da inclusão de temas sobre a HFC na formação de professores, podemos destacar a formação de cidadãos conscientes, críticos e reflexivos acerca do seu papel na sociedade e para além disso, da sua importância enquanto profissional compromissado com a escola e, sobretudo, com a educação. Do mesmo modo, temos também como ponto favorável a essa coadunação entre a HFC e a formação do professor a humanização das ciências e as aproximações dos interesses do aluno e da sociedade. De acordo com Matthews (1995), quando esta se faz de maneira cuidadosa e séria pode sim promover junto aos jovens o desenvolvimento do pensamento crítico e a superação da falta de significados que, infelizmente, assola boa parte dos conteúdos de ciências em âmbito escolar, uma vez que, possibilita uma melhor compreensão da estrutura das ciências, bem como, suas especificidades e o seu lugar na organização intelectual.

Sendo assim, ao consideramos a Ciência dinâmica em constante transformação, entendemos que o mesmo acontece com a formação do professor, e essa requer um processo de atualização, consistindo de uma autoformação como requisito necessário da profissão docente. O professor de ciências precisa ser oportunizado em sua atuação profissional a investigar de forma individual e coletiva os problemas que assolam seu trabalho, encontrados ao longo do seu percurso profissional. É nesse sentido que os estudos da HFC tornam o ensino promissor, uma vez que é de extrema relevância o professor conhecer os processos de produção do conhecimento, em que tais processos não podem ser negligenciados ou omitidos.

Sob tal enfoque, no que consiste a relevância da HFC na qualificação do professor de ciências, Dias e Martins (2004) indicam a importância de elucidar aspectos da Filosofia e da metodologia da Ciência, como a impossibilidade de provar teorias, a mutabilidade e provisoriedade do conhecimento científico. De acordo com tais autores, essas discussões precisam ser levadas para a sala de aula, explicitando que a Ciência é influenciada por fatores sociais, políticos, econômicos, éticos e religiosos. E dessa maneira, a HFC pode oportunizar o entendimento da natureza da atividade científica, perpassando pela dinâmica dos processos de construção do conhecimento. Por sua vez, a inserção da HFC é um possível caminho para que o Ensino de Ciências seja pautado na construção da cidadania e democracia (BASTOS, 1998; CALUZI et al., 2007). Entretanto, é difícil produzir um professor de Ciências historicamente, uma vez que nos cursos de 
formação a HFC ainda é concebida de forma tradicional, ou não é concebida (MARQUES, 2015).

Diante do exposto até aqui, a formação do professor precisa ser melhor repensada de modo que a abordagem histórica e filosófica seja trazida para os cursos de formação. O professor também necessita se instrumentar de materiais e subsídios que possam ser utilizados no seu fazer diário de sala de aula, nas situações em que permitam incluir os elementos da HFC, não se atendo ao simples caráter ilustrativo, esporádico, factual e tecnológico dos fenômenos científicos.

\section{3- DELINEAMENTOS METODOLOGICOS E DISCUSSÕES}

\subsection{A seleção dos artigos}

É oportuno ressaltar que ao realizarmos análises de trabalhos anteriormente publicados evidenciamos a evolução da temática ao longo de um determinado período, contribuindo assim, na divulgação e apropriação do tema estudado. Dessa maneira, esse trabalho se constituiu como sendo um trabalho de "Revisão de Literatura" (FIGUEREDO, 1990). As revisões preenchem dois papeis interligados, isto é, possuem função histórica e função de atualização. A primeira função refere-se ao desenvolvimento da ciência e, a segunda por sua vez, referese ao fornecimento de informações sobre o desenvolvimento corrente da ciência e sua literatura aos profissionais de qualquer área.

De acordo com Trentini e Paim (1999), as buscas de textos de literatura são importantes e necessárias para apoiar decisões de estudo, investigar dúvidas, verificar as discussões e a posição de ideias de autores sobre uma questão, atualizar conhecimentos, reorientar o enunciado de um problema, além de conhecer novas metodologias que possam subsidiar trabalhos científicos.

Ao longo desse estudo, buscamos realizar uma revisão bibliográfica sobre as pesquisas que tem como foco a contribuição da História e Filosofia da Ciência (HFC) na Formação de Professores (FP) de Ciências e Física. Cabe destacar que a inclusão das pesquisas sobre Ensino de Física refere-se à área de interesse de formação da autora e, portanto, merece tal investigação. Sendo assim, procuramos identificar e descrever os artigos publicados em periódicos científicos nos últimos onze anos (2004 - 2015), contemplando assim, um pouco mais que uma década de pesquisa na área de Educação em Ciências e Física.

Vale ressaltar que, essa busca foi realizada nos principais periódicos nacionais da área, a partir do sistema de avaliação Qualis da Coordenação de Aperfeiçoamento de Pessoal de Nível Superior - CAPES, e que também apresentassem versão online para facilitar o acesso aos exemplares. Salientamos que, apesar do número de periódicos que se enquadram nesse recorte ser bastante significativo, optamos pela seleção e análise de nove revistas. Destacamos a seguir os periódicos verificados e os seus respectivos volumes.

a) Revista Ciência e Educação (C\&E): volume 10 - 2004 ao volume 21 2015;

b) Revista Ensaio Pesquisa em Educação em Ciências (Ensaio): volume 6 2004 ao volume $17-2015$ 
c) Revista Investigação em Ensino de ciências (IENCI): volume 9 - 2004 ao volume 20 - 2015;

d) Revista Brasileira de Pesquisa em Educação em Ciências (RBPEC): volume 4- 2004 ao volume 15 - 2015;

e) Caderno Brasileiro de Ensino de Física (CBEF): volume 21 - 2004 ao volume 32 - 2015;

f) Revista Brasileira de Ensino de Física (RBEF): volume 26 - 2004 ao volume 37 - 2015;

g) Revista Electrónica de Enseñanza de las Ciencias (REEC): volume 3 - 2004 ao volume 14 - 2015;

h) Revista Experiências em Ensino de Ciências (EENCI): volume 1 - 2006 ao volume $10-2015$.

i) Revista Brasileira de Ensino de Ciências e Tecnologias (RBECT): volume 1 -2008 ao volume $8-2015$.

Assim, foram selecionados nove periódicos com Qualis A e B: Revista Ciência e Educação, Revista Ensaio: Pesquisa em Educação em Ciências, Revista Investigação em Ensino de Ciências, Revista Brasileira de Pesquisa em Educação em Ciências, Revista Electrónica de Enseñanza de las Ciencias, Caderno Brasileiro de Ensino de Física, Revista Brasileira de Ensino de Física, Revista Experiências em Ensino de Ciências e a Revista Brasileira de Ensino de Ciências e Tecnologia.

\subsection{Instrumento de análise e interpretação dos artigos}

Para análise e interpretação dos dados optou-se pela Análise de Conteúdo (AC), que possui métodos específicos a serem empregados (BARDIN, 1977; MORAES, 1999). A AC possui como matéria-prima qualquer material proveniente de comunicação verbal e não-verbal, como por exemplo cartas, cartazes, jornais, revistas, informes, livros, relatos dos diversos tipos, gravações, entrevistas, diários, vídeos, etc. Contudo, as informações advindas dessas variadas e diversificadas fontes chegam ao investigador em seu estado bruto, necessitando serem processados de maneira a facilitar o trabalho de compreensão, interpretação e inferência que demanda a AC (MORAES, 1999).

De maneira geral, os processos constituintes da AC podem ser divididos em quatro etapas (BARDIN, 1977): i) pré-análise; ii) codificação; iii) categorização e iv) análise dos resultados. Na pré-análise, faz-se a escolha dos documentos que serão submetidos à análise, a formulação das hipóteses e dos objetivos que fundamentarão as interpretações finais. Nessa etapa, os dados não são considerados inteiramente dados, mas precisam ser preparados de forma adequada para tal, assumindo uma função primordial para os objetivos da pesquisa. A segunda etapa diz respeito à codificação, que consiste na transformação dos dados que estão em "estado bruto" no texto. Tal transformação que pode ocorrer através de recorte, agregação e enumeração, permitindo atingir uma representação do conteúdo ou da sua expressão acerca das características do texto.

A terceira etapa é dada pela organização dos elementos codificados de acordo com categorias estabelecidas; dedução e por fim, a interpretação dos dados tratados nas etapas anteriores. O que permite o agrupamento dos elementos constituintes é a parte comum existente entre eles. Esse processo 
envolve duas etapas: o inventário, que consiste no isolamento dos elementos e a classificação, em que repartem os elementos, impondo a organização certa aos trechos. E por último, temos a análise que procura atingir uma compreensão mais aprofundada do conteúdo das mensagens através da inferência e interpretação.

\subsection{Resultados}

O período em que foi realizada a busca nos periódicos foi de 2004 a 2015. Sendo assim, abrangemos os volumes das revistas utilizadas correspondentes a tal período e obtivemos um total de 3.664 artigos. Deste montante, 14 artigos $(0,4 \%)$ tiveram como propósito discutir as contribuições da História e Filosofia da Ciência na Formação de Professores. Evidencia-se assim, uma lacuna em relação ao ensino e a inserção da HFC nos cursos de formação de professores e a utilização dos conteúdos históricos nas práticas docentes. Contudo, vale salientar que essa lacuna em âmbito das pesquisas educacionais, em educação em Ciências, já foi sinalizada em outros trabalhos, como por exemplo, Martins (2007), Hottecke e Silva (2011), Forato e colaboradores (2012) e Moura (2012). De modo geral, essas pesquisas apontam dificuldades dos professores em utilizar a HFC com parte integrante de suas disciplinas, mesmo reconhecendo a sua importância. De acordo com Martins (2007), não basta inserir tal abordagem nos cursos de formação sem que esse processo não passe por uma reflexão crítica e pormenorizada.

Dando continuidade, foram analisados títulos, palavras-chave resumos e, muitas vezes, quando necessário, o texto na íntegra, pois nem sempre essas informações davam subsídios suficientes para que fossem escolhidos de imediato. Vale ressaltar que a busca foi realizada diretamente no site dos periódicos selecionados. Nessa perspectiva, debruçamo-nos em verificar e discutir as características gerais dos artigos, as metodologias utilizadas pelos autores, além da relação da temática com a formação inicial e continuada de professores e como esses são refletidos nos currículos dos cursos de licenciaturas. A análise dos artigos constituiu-se em duas fases distintas: a primeira se referiu à fase descritiva, que permitiu identificar a quantidade de artigos por periódico e as metodologias utilizadas na construção das pesquisas. A segunda fase foi interpretativa, que consistiu nas discussões teóricas abordadas pelas publicações e os sujeitos participantes. Constatamos que os artigos apresentam como objetivos fomentar e discutir a formação de professores através da abordagem da História da Ciência.

\subsubsection{Número de artigos por periódicos}

A seguir, apresentamos um quadro geral da produção científica das revistas ao longo desses onze anos, como consta na Tabela 1:

Tabela 1- Produção Científica total apresentada nas nove revistas analisadas, no período de 2004 a 2015.

\begin{tabular}{|c|c|c|c|c|c|c|c|c|c|c|c|c|c|}
\hline Revista/Período & 2004 & 2005 & 2006 & 2007 & 2008 & 2009 & 2010 & 2011 & 2012 & 2013 & 2014 & 2015 & TOTAL \\
\hline C\&E & 40 & 36 & 24 & 28 & 36 & 39 & 45 & 60 & 60 & 60 & 60 & 63 & 551 \\
\hline Ensaio & 9 & 15 & 12 & 18 & 18 & 18 & 27 & 27 & 32 & 34 & 33 & 27 & 270 \\
\hline IENCI & 13 & 17 & 18 & 18 & 18 & 24 & 36 & 36 & 21 & 32 & 34 & 32 & 299 \\
\hline RBPEC & 24 & 15 & 12 & 12 & 18 & 20 & 22 & 30 & 30 & 29 & 44 & 30 & 286 \\
\hline CBEF & 65 & 20 & 19 & 20 & 27 & 31 & 33 & 29 & 56 & 34 & 41 & 49 & 424 \\
\hline RBEF & 62 & 79 & 67 & 78 & 63 & 64 & 65 & 92 & 77 & 111 & 91 & 97 & 946 \\
\hline REEC & 23 & 21 & 22 & 30 & 40 & 58 & 96 & 29 & 33 & 27 & 19 & 21 & 419 \\
\hline EENCI & $\mathrm{x}$ & $\mathrm{X}$ & 18 & 18 & 18 & 24 & 36 & 36 & 21 & 32 & 29 & 31 & 263 \\
\hline RBECT & $\mathrm{X}$ & $\mathrm{X}$ & $\mathrm{X}$ & $\mathrm{X}$ & 20 & 21 & 18 & 18 & 19 & 43 & 28 & 39 & 206 \\
\hline TOTAL & 236 & 203 & 192 & 222 & 258 & 299 & 378 & 357 & 349 & 402 & 379 & 389 & 3664 \\
\hline
\end{tabular}


Observa-se que, dentre as revistas de EC analisadas, a Revista Ciência e Educação apresenta um maior número de produção com um total de $15 \%$ e em segunda colocação a Revista Electrónica de Enseñanza de las Ciencias, com um percentual de $11 \%$ das produções. Em seguida, as demais: Revista Investigação em Ensino de ciências com 8\%; Revista Brasileira de Pesquisa em Educação em Ciências com 7,8\%; Revista Experiências em Ensino de Ciências com 7\%; Revista Brasileira de Ensino de Ciências e Tecnologia com 5,6\% e por último a Revista Ensaio Pesquisa em Educação em Ciências com um percentual de 0,7\%. Vale ressaltar que, a revista que se destaca com um valor total de 946 publicações é a Revista Brasileira de Ensino de Física, que embora seja uma revista exclusiva do Ensino de Física há publicações equivalendo a $26 \%$ do total, em seguida, o Caderno Brasileiro de Ensino de Física com 11\% das publicações.

Foram analisados 1.576 artigos nas revistas de Ensino de Física e 2.088 nas revistas de Ensino de Ciências. A relação dos trabalhos classificados e analisados referentes à Formação de Professores e as contribuições da HFC encontram-se na Tabela 2:

Tabela 2: Total de trabalhos analisados nos periódicos e trabalhos relacionados à FP e HFC.

\begin{tabular}{lcccccccccc}
\hline \multicolumn{1}{c}{ Periódico } & C\&E & Ensaio & IENCI & RBPEC & CBEF & RBEF & REEC & EENCI & RBECT & TOTAL \\
\hline $\begin{array}{l}\text { Total de } \\
\text { artigos } \\
\text { analisados }\end{array}$ & 551 & 270 & 299 & 286 & 424 & 946 & 419 & 263 & 206 & $\mathbf{3 . 6 6 4}$ \\
\hline $\begin{array}{l}\text { Artigos } \\
\begin{array}{l}\text { relacionados à } \\
\text { temática }\end{array}\end{array}$ & 3 & 0 & 3 & 1 & 3 & 1 & 1 & 1 & 1 & $\mathbf{1 4}(0,4 \%)$ \\
\hline
\end{tabular}

Das publicações encontradas nesse levantamento, 64\% do total (9 dentre os 14) de trabalhos são relacionados especificamente para a contribuição da HFC nos cursos de formação de professores de Física. Nessa perspectiva, a distribuição dos trabalhos nos demais cursos apresentou a seguinte forma: aproximadamente $21 \%$ deles relacionavam à formação de futuros licenciados em Química; $8 \%$ relacionados aos cursos de Biologia e 7\% aos professores das séries iniciais.

Em resumo, existe de fato demanda pelo estudo da HFC nas bases consultadas, entretanto pode-se compreender que, nesse recorte temporal realizado por nós, a temática ainda é uma lacuna, um tópico que requer ser muito mais debatido.

\subsubsection{Metodologias utilizadas pelas publicações analisadas}

A necessidade de refletir sobre a realização de pesquisas bibliográficas, se revela tão importante quanto discutir o "como" essas são realizadas, isto é, por onde e quais caminhos percorrer para alcançar os objetivos propostos (PRESTES 2012). A construção e o desenvolvimento de uma pesquisa científica consistem em uma tarefa árdua, permeada de surpresas e desafios que o pesquisador deve se atentar para que possa ser percebido e solucionado com possibilidades criativas e coerentes. Sendo assim, com base em tais argumentos, entendemos que se faz relevante discutirmos e apresentarmos uma breve descrição a respeito de como os quatorze artigos selecionados e analisados destacam e constroem seus respectivos delineamentos metodológicos nas pesquisas sobre FP, utilizando subsídios teóricos da HFC. 
Em relação ao tipo de pesquisa, encontramos três (03) artigos que se intitulam como sendo de abordagem qualitativa (DUARTE, 2004; PEREIRA; MARTINS, 2011), que de acordo com Bogdan e Biklen (1982) o ambiente natural como fonte dados é a sala de aula e possui como o objetivo a descrição de fenômenos, levando aos alunos a uma "enculturação" científica. Dentre esses, dois (02) artigos analisados utilizam a pesquisa bibliográfica e um (01) utiliza o estudo de caso como procedimentos metodológicos (GIL, 2008). Sobre a pesquisa bibliográfica, a mesma desenvolve-se a partir de materiais já elaborados constituídos principalmente de livros e artigos científicos. A autora Duarte (2004) ao propor investigar as práticas de professores portugueses e suas percepções relativamente à sua formação e à importância conferida à História da Ciência, se debruça em analisar de forma qualitativa os currículos desses professores de ciências, além de utilizar resultados de diversos estudos sobre o tema. Nessa perspectiva, Pereira e Martins (2011) analisam a estrutura curricular dos cursos de licenciatura em Física e em Química da Universidade Federal do Rio Grande do Norte (UFRN) no que se refere à inserção de disciplinas de conteúdo histórico e filosófico.

O artigo que utiliza o estudo de caso é apresentado por Rosa e Martins (2007). Esse procedimento metodológico consiste no estudo profundo e exaustivo de um ou poucos objetos, de maneira que permita seu amplo e detalhado conhecimento (GIL, 2008). As autoras analisaram através de um estudo de caso comparativo, como se dá a inserção de HFC no curso de Licenciatura em Física da Universidade Federal da Bahia (UFBA) e da UFRGS (Universidade Federal do Rio Grande do Sul). Justificam a escolha do procedimento devido às características do objeto de investigação: a percepção que esses professores de Física apresentam em relação à HFC.

Em relação aos objetivos metodológicos dois (02) trabalhos apresentam características exploratórias (GIL, 2008). Este tipo de pesquisa tem como objetivo proporcionar maior familiaridade com o problema, com vistas a torná-lo mais explícito ou a construir hipóteses. Nesse sentido, Martins (2007) utiliza da pesquisa exploratória para alcançar seu objetivo de investigar as principais dificuldades e experiências de três grupos de indivíduos acerca do uso da História e da Filosofia da Ciência para fins didáticos. Para tal, essencialmente investigou um universo de oitenta e dois (82) sujeitos, classificados em três grupos distintos de licenciandos, pós-graduandos e professores da rede pública. O outro trabalho a ser destacado (FERNÁNDEZ et al., 2010) apresenta um estudo com base em um grupo de 74 licenciandos em Química com o intuito de analisar os fatores que influenciam o pensamento desses professores em formação inicial sobre as implicações educacionais da inclusão da História da Química em sequências de ensino. Desse modo, a escolha da pesquisa exploratória permite um levantamento, recolhendo informações de todos os integrantes do universo pesquisado, tendo-se assim, um consenso acerca do problema estudado.

Diferentemente dos demais trabalhos apresentados anteriormente, um (01) trabalho faz uso da pedagogia de projetos (ALMEIDA, 2001) e outro utiliza o Vê de Gowin (GOWIN; ALVAREZ, 20005). Sobre o primeiro trabalho, o autor (RAPOSO, 2014) buscou uma abordagem didática em que o aluno assumisse o papel de protagonista no próprio processo de aprendizagem, e de colaborador no aprendizado de seus colegas de curso e de alunos de nível médio de uma escola pública parceira do projeto. O objetivo a partir de tal abordagem foi de tornar 
mais efetiva à aprendizagem da HFC e Natureza da Ciência (NDC) pelos licenciandos em Física e pelos alunos da escola parceira. Cabe destacar que na pedagogia de projetos o sujeito aprende no processo de produzir, de levantar dúvidas, de pesquisar e de criar relações, que incentivam novas buscas, descobertas, compreensões e reconstruções de conhecimento (PRADO, 2005).

Sobre o segundo trabalho destacado anteriormente, as autoras (BATISTA; NASCIMENTO, 2011) investigam a construção de uma abordagem didáticametodológica a partir do uso da História da Ciência associada com atividades experimentais, apresenta como estruturação metodológica o Vê Epistemológico de Gowin. De acordo com Moreira e Buchweitz (1983), essa estruturação ajuda os estudantes a compreenderem o cerne do conhecimento e o modo como é produzido.

Cabe destacar que os demais trabalhos que totalizam cinco (05) artigos, não definem explicitamente o tipo de pesquisa. Entretanto, tais produções subentendem-se no desenvolvimento metodológico características da pesquisa qualitativa, embora não sejam explicitadas de forma clara. Os pesquisadores que utilizam da abordagem qualitativa, de acordo com Gerhardt e Silveira (2009), preocupam-se com os aspectos constituintes da realidade que não podem ser quantificados, focalizando-se no entendimento e explicação da dinâmica das relações sociais.

Sobre os instrumentos de obtenção das informações encontramos quatro (04) trabalhos (PEREIRA; MARTINS, 2011; MASSONI et al., 2007, 2007; TOBALDIN et al., 2011) que utilizam a observação e a observação participante; três (03) artigos (PEREIRA; MARTINS, 2011; ROSA; MARTINS, 2007; TOBALDINI et al., 2011) utilizam as entrevistas semiestruturada, com licenciandos, pós-graduandos e professores da educação básica; ainda, cinco (05) artigos discorrem sobre experiências didáticas no nível superior e médio (RAPOSO, 2014; GATTI, 2004, 2010; MASSONI et al., 2007, 2007) e por fim, foram encontrados trabalhos que fazem uso de questionários, totalizando três (03) publicações (GURGEL; MARIANO, 2008; ROSA; MARTINS, 2007; TOBALDINI et al., 20011).

É notório que os trabalhos utilizam mais do que um instrumento de coleta de informações, algo considerado plausível, uma vez que, Carvalho (2011) destaca a importância da utilização de no mínimo três instrumentos nas pesquisas de Ensino de Ciências com o objetivo de fazer a triangulação dos dados combinando diferentes maneiras de ver um dado fenômeno.

\subsection{Discussão através das análises teóricas e empíricas dos artigos}

A utilização da História e Filosofia da Ciência vêm sendo valorizada cada vez mais por professores e educadores nos mais variados níveis de ensino. Esta valorização surge em resposta ao abismo existente entre as propostas inovadoras e as práticas de ensino desenvolvidas em sala de aula, em especial nos cursos de nível médio (GATTI et al., 2004). De acordo com Levy e Sanmartí (2001), os cursos de formação de professores, tanto inicial quanto continuada, ainda não conseguem de fato oportunizar mudanças significativas de posturas e ações frente aos processos de ensino e aprendizagem. $O$ uso de abordagens de essência histórica e filosófica da Ciência tem permitido uma gama de possibilidades perante aos diversos interesses de ensino. O interesse de educadores e professores permite a reflexão e discussão da gênese, além da transformação de 
conceitos referentes à natureza, técnicas, sociedades, bem como a análise e formulação dos modelos de conhecimentos (BELTRAN et al., 2014).

Nossa análise está voltada para os trabalhos relacionados à contribuição da HFC na Formação de Professores de Ciências e Física, de forma que se pretende traçar características sobre a utilização e os subsídios para a FP, bem como as metodologias empregadas pelos autores, os espaços de formação, sejam na Formação Inicial e/ou Continuada, e como essas discussões permeiam os currículos das licenciaturas. Dentro dessa ótica, a análise realizada na seção anterior nos permitiu identificar dos quatorze (14) artigos, tais características. A seguir, apresentamos um breve resumo de alguns desses trabalhos e algumas considerações sobre o uso desta temática nos cursos de formação de professor.

No que se refere aos estudos que levam em consideração as discussões sobre a formação inicial e continuada de professores, destacamos os trabalhos elaborados pelos autores Gattl et al. (2004); Duarte (2004); Gurgel e Mariano (2008); Fernández et al (2010); Raposo (2014); Martins (2007); Massoni et al. (2007); Nardi e Silva (2010); Moreira et al. (2007); Tobaldini et al. (2011); Batista et al. (2011) e Kneubil e Ricardo (2014). Aqueles que dizem respeito aos aspectos do currículo nos cursos de licenciatura, destacamos Duarte, 2004; Pereira e Martins, 2011; Rosa e Martins, 2007. É notório que há um número significativo de trabalhos referentes às discussões da temática HFC nos cursos de Formação, entretanto nesses trabalhos observamos que algumas discussões perpassam a importância da inclusão da HFC nos currículos de FP postas pelas licenciaturas, e que porventura também poderemos citar ao longo do texto.

A respeito dos cursos de formação promovidos nessas pesquisas Gatti et al., (2004) inserem a discussão sobre a HFC na disciplina de Prática de Ensino de Física, para licenciandos, a partir de um curso de formação tendo como pano de fundo o desenvolvimento histórico do tema atração gravitacional. Neste estudo, os autores evidenciam as dificuldades para uma postura na ação docente e propõem um modelo de formação que favoreça a adoção de metodologias de ensino voltadas para construção de conhecimentos, balizadas pela a inserção da HFC. A formação do professor, quando perpassa por essas discussões, permite a um exercício profissional docente de múltiplas vantagens e utilidades relacionadas principalmente com o aumento da qualidade da aprendizagem de professores e alunos. De certo modo, a historiografia da Ciência pode melhorar a compreensão dos docentes oportunizando assim, uma visão mais humana da ciência e do seu progresso. Essa pesquisa teve em 2010 uma ampliação, também realizada por Gatti e seus colaboradores.

Ainda nessa perspectiva, os autores Fernández, Gatica e Blancafort (2010) colocam em discussão a pouca reflexão em torno do modelo de Ciência que tem os estudantes. Tal situação é devido à reprodução por parte dos professores em utilizarem unicamente os livros didáticos como fonte de pesquisa em suas aulas. Apesar da existência de exemplos acerca do uso da História, os mesmos, em sua maioria, apresentam estes como simples recortes de elementos de uma determinada Ciência. Esses elementos são evidenciados sem fazer referência à própria História da Ciência abordada, e são apresentados apenas como mero "surgimento" empobrecido de forma descontextualizada da superação de teorias, em que uma nova teoria "derruba" a teoria aceita anteriormente. Além disso, muitas vezes, há uma representação caricatural de aspectos da biografia dos cientistas, ou apenas em representação de fotos dos mesmos (DIAS; 
MARTINS, 2004). Nesse sentido, perpetuam-se as visões deformadas da Natureza da Ciência seu objeto e método de estudo.

A propósito destas informações, é possível fazermos inferências com base no trabalho das autoras Gurgel e Mariano (2008) que nos dizem que as práticas de ensino, adotadas por esses professores, podem de alguma maneira ter influenciado de forma direta e indireta, os modos como hoje lecionam Ciências e os tópicos derivados da mesma, como por exemplo a HFC. Essas afirmações tornam-se mais evidentes a partir de um estudo que surgiu do interesse de problematizar algumas respostas apresentadas por 67 futuros professores de Ciências (Química e Biologia) sobre a neutralidade e objetividade da Ciência e Tecnologia (GURGEL; MARIANO, 2008). As autoras constataram em seus resultados visões distorcidas por parte dos licenciandos, além de que os mesmos consideraram que a solução dos problemas sociais está baseada em critérios científicos e tecnológicos. Em contrapartida, apontam caminhos para a superação dessas lacunas, uma vez que, a Ciência e Tecnologia apresentam-se como áreas que possibilitam análises dos processos de construção social, cultural, tecnológica e histórica da Ciência, e não menos importante, das concepções de currículo. Enfatizam a necessidade de mudanças nos cursos de formação de professores, perpassando por uma compreensão social, política da Ciência e Tecnologia.

Em outra análise, observou-se também, a fragilidade das concepções dos professores e futuros professores de Ciências no trabalho de Tobaldini et al. (2011). Ao investigarem a história e epistemologia da ciência de professores formadores e alunos do curso de ciências biológicas. Indicaram inicialmente, que os grupos de participantes apresentavam visões simplistas da ciência. Estes resultados evidenciaram para os autores, uma forma de oportunizar para os professores e alunos discussões acerca da ciência, por meio de grupos de pesquisa em epistemologia da ciência no contexto universitário. Ao estabelecerem relações entre conceitos emitidos pelos professores formadores e alunos, constatou-se uma similaridade de discurso simplista do que é ciência, os seus objetivos e finalidades. Destacam ainda, a forte evidência da categoria empírico-indutivista. Tal aspecto também foi observado nos estudos de Pórlan, García e Del Pozo $(1997,1998)$, que diz respeito ao conhecimento profissional e epistemológico dos professores. Os autores discutem os obstáculos que permeiam a prática docente, que perpassam desde a visão empirista da ciência ao absolutismo científico, além da promulgação da Ciência objetiva, acabada, descontextualizada, neutra, fragmentada e simplória.

Esses resultados possibilitam a compreensão das dificuldades encontradas no âmbito do ensino de ciências na construção da ciência numa perspectiva histórica. Os sujeitos envolvidos nesses processos estão intrincados em trabalhos científicos e possuem dificuldades em explicitar em seus discursos aspectos sociais e subjetivos da ciência. Em síntese, faz-se necessário que a promulgação das discussões e trabalhos deva continuar a se intensificar, para que os resultados cheguem às escolas e às universidades, para que assim, os profissionais revejam suas práticas e teorias com o intuito de mudar os paradigmas a respeito do assunto (TOBALDINI et al., 2011).

Por sua vez, Batista e Nascimento (2011) construíram uma proposta de formação inicial de professores do curso de Pedagogia a partir do uso da HFC, associada com atividades de cunho experimental e que apresenta como hipótese de estruturação metodológica o Vê Epistemológico de Gowin. Os autores 
evidenciaram que esta metodologia, quando utilizada de maneira adequada, torna-se um instrumento relevante na formação de professores das séries iniciais. Neste trabalho, as atividades desenvolvidas demonstraram que a estratégia didático-metodológica utilizada àquela articulada com a HFC e com as atividades experimentais, é portanto, um instrumento relevante a ser usado na formação de professores. Do mesmo modo, Raposo (2014) realizou um conjunto de atividades de extensão juntamente com os alunos de licenciatura em Física do CEFET/RJ, a partir da proposta de ensino através da pedagogia de projetos. Objetivou-se tornar mais efetiva a aprendizagem de HFC e Natureza da Ciência pelos licenciandos e pelos alunos da escola parceira. A proposta despertou nos alunos interesse nas discussões e gerou debates práticos importantes para os licenciandos, referentes aos métodos e atividades didáticas apropriadas para o contexto do Ensino Médio e Graduação.

De acordo com Schirmer e Sauerwein (2014), as pesquisas sobre Ensino de Ciências devem estimular a construção de materiais atrativos, atividades dinâmicas que oportunizem diferentes recursos didáticos e metodológicos nas salas de aulas, podendo assim, ser mais explorados pelas pesquisas e práticas de ensino, estimulando os sujeitos a gostarem de Ciências. Os trabalhos citados (BATISTA; NASCIMENTO, 2011; RAPOSO, 2014) utilizam de propostas diferenciadas, aliadas ao tema HFC, com o intuito de auxiliar aos alunos a desenvolverem competências, aptidões e preferências a serem trabalhadas no ensino, tais como interpretação, atuação, pesquisas, de forma a atingir um público maior de estudantes (SCHIRMER; AS UERWEIN, 2014).

Em relação à relevância da inserção de temas da HFC nos currículos dos cursos de graduação, Guerra (2004) traz um debate significativo sobre as implicações da formação de professores de Ciências, na prática de professores portugueses, sob a luz da importância da análise curricular de formação. A autora traz resultados de alguns estudos sobre a utilização da HFC nas práticas pedagógicas, de forma geral, muitos deles continuam a omitir e a veicular a concepção do progresso científico como cumulativo e linear. Outro aspecto importante a ser citado, é o fato de alguns professores avaliarem sua formação em HFC como claramente deficitária. Esses aspectos também foram evidenciados por Pereira e Martins (2011) ao analisarem a estrutura curricular dos cursos de licenciatura em física e química da Universidade Federal do Rio Grande do Norte (UFRN). Os resultados mostraram distinção entre as licenciaturas em relação ao enfoque teórico-metodológico assumido pelos professores no trabalho com os conteúdos e principalmente, o papel desempenhado pela disciplina na estrutura curricular.

Nesses estudos, ambos autores discutem a formação precária e o histórico dos formadores de professores em relação aos conteúdos de HFC, assim como também, os modelos de formação subjacentes à estrutura curricular dos cursos. Paralelamente, Rosa e Martins (2007) analisaram o currículo de FP de Física da Universidade Federal da Bahia, e também evidenciaram em seus resultados, a necessidade de se pensar na formação continuada de docentes universitários ligados à formação inicial de professores de Física, particularmente no que se refere às discussões em HFC. Tais constatações demonstraram a relevância de voltar o olhar para a formação dos professores que participam da formação dos licenciados, e também, das necessidades dos Institutos pensarem na promoção de mecanismos que oportunizem formação continuada que contemplem as 
discussões contemporâneas de HFC. Essas pesquisas (GUERRA, 2004; PEREIRA; MARTINS, 2011; ROSA; MARTINS, 2007) chamam atenção para os programas de investigação continuada de professores, não somente para Educação Básica, mas também na Educação Superior.

No trabalho de Massoni e Moreira (2007) há uma compreensão descritiva e contextualizada da cultura de sala de aula de uma disciplina de História e Epistemologia da Física, do currículo de FP de Física. Essa observação durou um ano e se desdobra em quatro outros trabalhos, nos quais, em que o terceiro também foi considerado nas nossas análises (MOREIRA et al., 2007). Nessas pesquisas, também foi constatado a importância de a formação de professores perpassar discussões de cunho contemporâneo e epistemológico da HFC, bem como uma formação crítica e reflexiva.

Por isso tudo, sabemos que a incorporação da HFC no ensino de ciências de modo geral é bem aceita e difundida em âmbito acadêmico. Entretanto, essa realidade muda quando nos referimos a essa abordagem no campo de formação de professores de ciências, revelando-se assim, uma lacuna a ser superada na área. Nesse sentido, entendemos que os cursos de formação inicial e continuada precisam de fato oportunizar aos seus alunos uma compreensão mais elaborada e fundamentada a respeito da sua formação e da Ciência, viabilizando assim, a uma prática mais coerente com as exigências educacionais e de uma sociedade.

Levando em consideração todos esses aspectos, espera-se que através dessas discussões possamos de fato contribuir para a construção de práticas efetivas, no que concerne à inserção, utilização e promulgação dos construtos da HFC na formação de professores de ciências. Espera-se ainda minimizar as dificuldades em se utilizar essa abordagem como aporte teórico-metodológico nas vivências do professor. A HFC pode proporcionar aos sujeitos em formação um estudo mais adequado de equações e fórmulas relacionadas à conceitos e teorias, que geralmente se apresentam sem sentido e significado para os estudantes. Além de servir como uma importante ferramenta de trabalho das concepções alternativas dos alunos, mostrando a partir de seus elementos contextuais a dimensão coletiva do conhecimento (SILVA, 2010).

\section{CONSIDERAÇÕES FINAIS}

Apresentamos um panorama dos trabalhos publicados na área de Ensino de Ciências e de Física que contemplassem as pesquisas sob a temática da contribuição da História e Filosofia da Ciência na Formação de Professores de tais áreas. O estudo aqui exposto, constituiu-se na organização das informações coletadas em tabelas e breve descrição de treze dos quatorze artigos, através da Análise de Conteúdo, como proposto Bardin (1977) e Moraes (1999). Observouse que, dos 3.664 artigos publicados nos nove periódicos analisados, nos últimos onze anos, apenas 14 foram destinados às contribuições da HFC na FP de Ciências e Física. Nota-se a relevância desses pesquisadores em contribuir de forma mais significativa na formação de futuros professores, tanto nas possibilidades de melhorias do currículo, quanto na própria formação dos professores formadores.

Em vista dos aspectos levantados através dessas pesquisas, acerca das contribuições da HFC na formação de professores, podemos inferir que a inserção de temas referentes à HFC nos currículos dos cursos de licenciatura, 
quando realizada de forma cuidadosa e estimulante, possibilita uma formação mais adequada e abrangente sobre as Ciências. De tal forma, que facilita uma significativa intervenção em sala de aula, levando aos alunos uma compreensão mais adequada e coerente dos conteúdos científicos.

Desse modo, diante dessas discussões a respeito dos aspectos curriculares ressaltados pelas pesquisas analisadas e de modo geral, nota-se uma lacuna expressiva a ser preenchida por pesquisas futuras acerca da necessidade de abordar elementos históricos e filosóficos da Ciência nos cursos de formação de professores de Ciências, em âmbito nacional. Nesse sentido, os pesquisadores citados até aqui, concordam que tal abordagem pode fornecer importantes subsídios teóricos e metodológicos na formação de professores, tanto no que se refere à elaboração e implementação das atividades e estratégias didáticas, quanto na superação de obstáculos epistemológicos que assolam a profissão e o ensino de modo geral.

Apesar das diferentes perspectivas adotadas a respeito de como inserir a HFC no âmbito da formação de professores, torna-se imprescindível promover meios sólidos para que as propostas curriculares e de ensino de fato estimulem a investigação científica com concretude, contemplando os contextos históricos e filosóficos que englobam toda a construção do conhecimento científico (EL-HANI, 2006). Levando-se em consideração esses aspectos, é inegável que professores e pesquisadores de Ciências precisam de fato imergir em busca da construção de seu próprio conhecimento, de modo a compreender a Ciência como um processo histórico, cultural e humano. As pesquisas analisadas e discutidas ao longo desse trabalho apontam caminhos favoráveis, no que diz respeito à inserção de temas da HFC na formação de professores, mas é preciso que esses resultados tornemse significativos e instigantes nos espaços formativos, aspectos bastante defendidos em todas as pesquisas.

Pode-se concluir, portanto, que é preciso ultrapassar os limites da história da ciência factual dos livros didáticos, embasada somente em curtas biografias dos cientistas mais famosos e das teorias aceitas hoje para, que de fato, a História e Filosofia da Ciência cumpra seu papel. Seu enfoque em sala de aula precisa derrubar estas barreiras, se quisermos que ela seja um instrumento importante e profícuo na construção do conhecimento e de um ambiente propício a reflexão e criticidade.

Para isso, partimos do pressuposto que é necessário que os futuros professores e professores em exercício consigam perpassar por uma formação que oportunize a experienciar os espaços históricos do assunto em questão, de maneira que passem a reconhecer os problemas e as controvérsias vividas pelos personagens ("cientistas") que construíram de forma direta ou indireta aquele conhecimento (GUERRA et al., 2004). Ainda, essa formação precisar proporcionar o estudo e elaboração de novas estratégias de ensino que possibilitem contribuir com uma maior significação ao estudo de conceitos e teorias científicas, demonstrando que a ciência e sua evolução são pensadas e repensadas por mais de uma pessoa, elucidando a dimensão coletiva do conhecimento. Ainda, oportunizando aos sujeitos tanto os acertos e erros cometidos ao longo da história na ciência. Salientando os problemas e dificuldades que assolam o cientista na formulação de uma teoria e seus dilemas (SILVA, 2010). 
Em síntese, acreditamos que este trabalho apresenta uma importante contribuição na visualização dos resultados e conclusões dessas pesquisas para as práticas efetivas na formação de professores e promulgação dos aspectos relacionados à História e Filosofia da Ciência. 


\title{
THE CONTRIBUTIONS OF HISTORY AND PHILOSOPHY OF SCIENCE IN TEACHER TRAINING: AN ANALYSIS IN PERIODICALS
}

\begin{abstract}
The present work presents data from an exploratory study that analyzed the academic production present in nine periodicals of Teaching of Sciences and Teaching of Physics, referring to the contributions of History and Philosophy of Science (HFC), in the courses of initial and continued training of teachers of Sciences. The period covered by this work comprised the years 2004 to 2015 . The objective was to evaluate how these contributions have been disseminated and addressed in teacher training courses in the last 11 years. We observed that only 14 papers were devoted to the contributions of HFC in Teacher Training in Science and Physics, revealing an expressive gap to be filled by future research. Our results point out favorable paths to the insertion of historical and philosophical themes in the formation of teachers, but it is necessary that these results become significant and instigating in the formative spaces, aspects defended quite well in all the researches.
\end{abstract}

KEYWORDS: Teacher training. History and Philosophy of Science. Science teaching. 
ALMEIDA, M.E.B. de. Como se trabalha com projetos (Entrevista). Revista TV ESCOLA. Secretaria de Educação a Distância. Brasília: Ministério da Educação, SEED, $\quad$ 22, março/abril, $2002 . \quad$ Disponível: <http://portal.mec.gov.br/seed/arquivos/pdf/tvescola/revistas/Revista22/PDF/en trevista.pdf>. Acesso em: 23 ago. 2016.

BARDIN, L. Análise de Conteúdo. Lisboa: Edições 70, 1977.

BELTRAN, M. H. R.; SAITO, F. ;TRINDADE, L. S. P. . História da Ciência para Formação de Professores. 1. ed. São Paulo: Editora Livraria da Física, 2014. v. 1. $128 p$.

BONZANINI, K. T.; BASTOS, F. Estratégias de formação continuada de professores: análise de uma experiência. Enseñanza de las Ciencias, v. extra, p. 448-453, 2013. Disponível:

http://www.raco.cat/index.php/Ensenanza/article/download/296354/385241>. Acesso em: 17 jan.2017.

BRASIL. Decreto no 6.755, de 29 de janeiro de 2009. Institui a Política Nacional de Formação de Profissionais do Magistério da Educação Básica. Brasília: Casa Civil da Presidência da República Federativa do Brasil/Subsecretaria para Assuntos Jurídicos,

Disponívelem:<http://www.planalto.gov.br/ccivil03/Ato20072010/2009/Decreto/ D 6755htm>. Acessado em: 21 jun. 2016.

BRASIL. Secretaria de Educação Básica - Ministério da Educação, Secretaria de Educação Básica. Orientações Curriculares para o Ensino Médio (2006). Volume 2. Ciências da natureza, matemática e suas tecnologias. Brasília.

CARLOS MARCELO, G. Pesquisa sobre a formação de professores: o conhecimento sobre aprender a ensinar. Revista Brasileira de Educação, n. 9, p. 51-75, set./out./nov./dez., 1998. Disponível $<$ https://idus.us.es/xmlui/bitstream/handle/11441/31832/Pesquisa_sobre_a_for ma\%C3\%A7ao_de_profesores.pdf?sequence=1\&isAllowed=y>. Acesso em: 15 ago.2016.

CARVALHO, A. M. P.; GIL-PEREZ, D. Formação de professores de ciências: tendências e inovações. 6. ed. São Paulo: Cortez, 2006.p. 13-63.

EL-HANI, C. N. Notas sobre História e Filosofia da Ciência na Educação Científica de Nível Superior. In: SILVA, C.C. (Org.). História e Filosofia da Ciência no Ensino de Ciências: Da Teoria à Sala de Aula. São Paulo: Editora Livraria da Física. 2006. p. 321. 
FORATO, T. C. M.; MARTINS, R. A.; PIETROCOLA, M. History and nature of science in high school: Building up parameters to guide educational materials and strategies. Science \& Education, v. 21, n. 5, p. 657-682, 2012.

GAGLIARDI, R.; GIORDAN, A. La História de las Ciencias: Una Herramienta para la Enseñanza. Enseñanza de las Ciencias, v.4 (3), p. 253-258, 1986.

GIL, A. C. Como elaborar projetos de pesquisa. 4. ed. São Paulo: Atlas, 2008.

GIL-PÉREZ, D. Que hemos de saber y saber hacer los profesores de Ciencias? Enseñanza de las Ciencias, Barcelona, v. 9, n. 1, p. 69-77, 1991. Disponível em: <http://www.raco.cat/index.php/Ensenanza/article/view/51357/93106>. Acesso em: 10 jan. 2017.

GIORDAN, A.; DE VECCHI. As Origens do Saber. Porto Alegre: Artes Médicas, 1996. GUERRA, A; REIS, C. J.BRAGA, M. Uma abordagem Histórico-Filosófica para o Eletromagnetismo no Ensino Médio. Caderno Brasileiro de Ensino de Física, v.21, p. 224-248, 2004

HÖTTECKE, D.; SILVA, C. C. Why implementing history and philosophy of science in school science education is a challenge: an analysis of obstacles. Science \& Education, v. 20, n. 3-4, p. 293-316, 2011.

LEVY, M. I. C. \& SANMARTí PUIG, N. Fundamentos de un modelo de formación permanente del profesorado de ciencias centrado en la reflexión dialógica sobre las concepciones y las prácticas. Enseñanza de las Ciencias, Barcelona, v. 19, n. 2, p. 269-283, 2001.2 Disponível em: <http://www.raco.cat/index.php/ensenanza/article/viewFile/21741/21574> Acesso em: 20 ago. 2016.

MARANDINO, M. A prática de ensino nas licenciaturas e a pesquisa em ensino de ciências: questões atuais. Caderno Brasileiro de Ensino de Física, v. 20, n. 2, p. 168-193, 2003.2 Disponível em: <http://www.raco.cat/index.php/ensenanza/article/viewFile/21741/21574>. Acesso em: 10 jul. 2016.

MARQUES, D. M. Formação de professores de ciências no contexto da História da Ciência. História da Ciência e Ensino: construindo interfaces, v. 11, p. 1-17, 2015. Disponível em: $<$ http://revistas.pucsp.br/index.php/hcensino/article/view/23020/16717>. Acesso em: 20 ago. 2016.

MARTINS, A. F. História e filosofia da ciência no ensino: há muitas pedras nesse caminho. Caderno Brasileiro de Ensino de Física, v. 24, n. 1, p. 112-31, 2007.

MELLADO, V. Concepciones y prácticas de aula de profesores de ciencias, en la formación inicial de primaria y secundaria. Enseñanza de las Ciencias, Barcelona, v. 14, n. 3, p. 289-302, 1996. Disponível em: 
<http://www.raco.cat/index.php/ensenanza/article/viewFile/21460/93425>. Acesso em 20 ago. 2016.

MORAES, R. Análise de Conteúdo. Educação, Porto Alegre, RS, v. XXII, n.37, p. 7 32, 1999.

MOURA, B. A. Formação crítico-transformadora de professores: uma proposta a partir da História da Ciência. 2012. Tese (Doutorado) - Universidade de São Paulo, São Paulo, 2012.

PEREIRA, José Everaldo; NUNEZ, Isauro Beltrán. As Necessidades Formativas de Professores de Ciências Naturais para Trabalhar a Linguagem Matemática Como Ferramenta para a Educação Científica dos estudantes do Ensino Médio. In: VI ENPEC - ENCONTRO NACIONAL DE PESQUISA EM EDUCAÇÃO EM CIÊNCIAS, 2007, FLORIANÓPOLIS. VI ENCONTRO NACIONAL DE PESQUISA EM EDUCAÇÃO EM CIÊNCIAS. BELO HORIZONTE: ABRAPEC, 2007.

PORLÁN, R., RIVERO, A. y MARTÍN DEL POZO, R. Conocimiento profesional y epistemología de los profesores I: Teoría, métodos e instrumentos. Enseñanza de las Ciencias, 15 (2), pp. 155-171, 1997. Disponível em: < http://www.raco.cat/index.php/ensenanza/article/viewFile/21488/93522>. Acesso em: 20 ago. 2016.

PORLÁN, R., RIVERO, A.; MARTÍN DEL POZO, R. Conocimiento profesional y epistemología de los profesores II: Estudios empíricos y conclusiones. Enseñanza de las Ciencias, 16(2), pp. 271-288, 1998. Disponível em: <http://www.raco.cat/index.php/ensenanza/article/viewFile/21488/93522>. Acesso em: 21 ago. 2016.

PRADO, M. E. B. B. Pedagogia de Projetos: Fundamentos e Implicações. In: Maria Elizabeth Bianconcini de Almeida; José Manuel Moran. (Org.). Integração das Tecnologias na Educação. Brasília, DF: Secretaria de Educação a Distância Ministério de Educação-MEC, 2005, v. , p. 12-17.

PRESTES, Z. R. O rigor metodológico em pesquisa bibliográfica. Ensino em Re-vista (UFU. Impresso), v. 19, p. 403-407, $2012 . \quad$ Disponível: <http://www.seer.ufu.br/index.php/emrevista/article/view/14947/8447>. Acesso em: 09 dez. 2016. Ciência em sala de aula: uma análise em periódicos de ensino nacionais. Revista Brasileira de Pesquisa em Educação em Ciências, v. 14, p. 61-77, 2014. Disponível em: < https://seer.ufmg.br/index.php/rbpec/article/view/2497>. Acesso em: 18 ago. 2016. 
SILVA, Boniek Venceslau da Cruz Silva. Controvérsias sobre a natureza da luz: uma aplicação didática. Dissertação de Mestrado. 2010. Dissertação de Mestrado apresentada ao Programa de Pós-Graduação em Ensino de Ciências Naturais e Matemática do Centro de Ciências Exatas e da Terra da Universidade Federal do Rio Grande do Norte, Universidade Federal do Rio Grande do Norte, Natal.

TRENTINI, M.; PAIM, L. Pesquisa em Enfermagem. Uma modalidade convergenteassistencial. Florianópolis: Editora da UFSC, 1999.

\section{REFERÊNCIAS ANALISADAS}

BATISTA, I. L.; NASCIMENTO, E. G. União da história da ciência com o vê de Gowin: um estudo na formação de professores das séries iniciais. Revista Brasileira de Pesquisa em Educação em Ciências, v. 11, p. 41-66, 2011. Disponível em: < https://seer.ufmg.br/index.php/rbpec/article/view/2400> . Acesso em: 07 jul. 2016.

DUARTE, M. C. A História da Ciência na prática de professores portugueses: Implicações para a formação de professores de Ciências. Ciência e Educação (UNESP), São Paulo, v. 10, n. 3, p. 317-331, 2004. Disponível em: <http://www.scielo.br/pdf/ciedu/v10n3/02.pdf>. Acesso em: 07 jul. 2016.

FERNÁNDEZ, L.C.; GATICA, M. Q.; BLANCAFORT, A. B. La importancia de la Historia de la Química en la enseñanza escolar: análisis del pensamiento y elaboración de material didáctico de profesores en formación. Ciência \& Educação (UNESP), v.16, n.2, p. 277-291, 2010. Disponível em: <http://www.scielo.br/scielo.php?script=sci_arttext\&pid=S1516$73132010000200001>$. Acesso em: 07 jul. 2016.

GATTI, S. R. T.; NARDI, R. ; SILVA, D. A história da ciência na formação do professor de física: subsídios para um curso sobre o tema atração gravitacional visando às mudanças de postura na ação docente. Ciência e Educação (UNESP. Impresso), v. 10, n.3, p. 491-500, 2004. Disponível em: <http://www.scielo.br/scielo.php?script=sci_arttext\&pid=S1516$73132004000300012>$. Acesso em: 07 jul. 2016.

GATTI, S. R. T.; NARDI, R. ; SILVA, D. História da ciência no ensino de Física: um estudo sobre o ensino de atração gravitacional desenvolvido com futuros professores. Investigações em Ensino de Ciências (UFRGS), v. 15, p. 7-59, 2010. Disponível em: http://www.if.ufrgs.br/ienci/artigos/Artigo_ID227/v15_n1_a2010 >. Acesso em: 07 jul. 2016. 
inserção da História e Sociologia da Ciência na construção do conhecimento científico. Revista Brasileira de Ensino de Ciência e Tecnologia (UTFPR), v. 1, p. 59-72, 2008. Disponível em: <https://periodicos.utfpr.edu.br/rbect/index >. Acesso em: 08 jul. 2016.

KNEUBIL, F. B.; R., E. A Relevância do Ensino sobre a Ciência: relato de uma experiência em um curso universitário de eletromagnetismo. Experiências em Ensino de Ciências (UFRGS), v. 9, p. 170-186, 2014. Disponível em: < http://if.ufmt.br/eenci/?go=artigos\&idEdicao=38>. Acesso em: 07 jul. 2016.

MARTINS, A. F. P.. História e Filosofia da Ciência no ensino: há muitas pedras nesse caminho....Caderno Brasileiro de Ensino de Física, v. 24, p. 112-131, 2007. Disponível em: <https://periodicos.ufsc.br/index.php/fisica/article/viewFile/6056/12761>. Acesso em: 07 jul. 2016.

MASSONI, N. T.; MOREIRA, M. A. O cotidiano da sala de aula de uma disciplina de História e Epistemologia da Física para futuros professores de Física. Investigações em Ensino de Ciências (Online), v. 12, p. 7-54, 2007. Disponível em: < http://www.if.ufrgs.br/ienci/artigos/Artigo_ID160/v12_n1_a2007.pdf>. Acesso em 08 jul. 2016.

MOREIRA, M. A. ; MASSONI, N. T. ; OSTERMANN, F. . História e epistemologia da Física na licenciatura em física: uma disciplina que busca mudar concepções dos alunos sobre a natureza da ciência. Revista Brasileira de Ensino de Física (Impresso), v. 29, p. 127-134, 2007. Disponível em: <http://www.scielo.br/scielo.php?script=sci_arttext\&pid=S1806$11172007000100019>$. Acesso em: 08 jul. 2016.

PEREIRA, G. J. S. A.; FERRER, ANDRÉ FERRER P. A inserção de disciplinas de conteúdo histórico-filosófico no currículo dos cursos de licenciatura em Física e em Química da UFRN: uma análise comparativa. Caderno Brasileiro de Ensino de Física, v. 28, p. 229-258, 2011. Disponível em: $<$ https://periodicos.ufsc.br/index.php/fisica/article/view/21757941.2011v28n1p229>. Acesso em: 08 jul. 2016.

RAPOSO, W. História e Filosofia da Ciência na Licenciatura em Física, uma proposta de ensino através da pedagogia de projetos. Caderno Brasileiro de Ensino de Física, $2014 . \quad$ Disponível em:<https://periodicos.ufsc.br/index.php/fisica/article/view/21757941.2014v31n3p722>. Acesso em: 08 jul. 2016. 
<https://www.if.ufrgs.br/cref/ojs/index.php/ienci/article/view/463 >. Acesso em: 08 jul. 2016.

TOBALDINI, B. G.; CASTRO, L. P. V. ; JUSTINA, L. A. D. ; MEGLHIORATTI, F. A. . Aspectos sobre a natureza da ciência apresentados por alunos e professores de licenciatura em ciências biológicas. REEC. Revista Electrónica de Enseñanza de las
Ciencias,
v. 10,
p. 457-480,
2011.
Disponível
em:

<http://reec.uvigo.es/volumenes/volumen10/REEC_10_3_4.pdf> Acesso em: 08 jul. 2016.

\footnotetext{
Recebido: 2017-01-26

Aprovado: 2017-10-06

DOI: 10.3895/rbect.v10n3.5365

Como citar:

SANTOS, L. S. B.; PEIXOTO, C. A. S.; BELLO, M. E. R. B.; GUZZI FILHO, N. J., As contribuições da

História e Filosofia da Ciência na Formação de Professores: uma análise em periódicos. Revista Brasileira de Ensino de Ciência e Tecnologia, v. 10, n. 3, 2017. Disponível em:

<https://periodicos.utfpr.edu.br/rbect/article/view/5365 >. Acesso em: 21/02/2018.

Correspondência: Laura Sued Brandão Santos - laurasantos08@gmail.com

Direito autoral: Este artigo está licenciado sob os termos da Licença Creative Commons-Atribuição 4.0 Internacional.
}

\section{(c) (1)}

